\title{
Best practices for selection and application of firefighting foam
}

\author{
Joanna Rakowska ${ }^{1, *}$ \\ ${ }^{1}$ The Main School of Fire Service, Faculty of Civil Safety Engineering, 52/54 Slowackiego St., \\ 01-629 Warsaw, Poland
}

\begin{abstract}
The article provides studies concerning the selection for the usage of firefighting foam in the aspect of human, property, environmental safety and sustainable development. Foam concentrates are products of the chemical industry, which, due to the type of raw materials, technology, usage method and waste disposal involved, are an important element of the industrial and environmental safety. Considering the range of extinguishing concentrates available on the market, with their different scope and performance effectiveness, it is necessary to responsibly plan purchases of required extinguishing agents. For testing all types of firefighting foam agent: synthetic, aqueous film forming, protein, fluoroprotein and fluoroprotein film forming concentrates were used. The standard test method ISO 7203-1:2011 for low-expansion foams used for the control, extinction and inhibition of reignition of fires of waterimmiscible liquids was applied. The use of an appropriately selected and properly concentrated firefighting foam to extinguish a fire allows decreasing the duration of the fire and its consequences for the environment. The amount of used extinguishing agents will be substantially smaller. In the article the impact of considered use of firefighting foams on their effectiveness and potential dangers resulting from an inappropriate choice was shown.
\end{abstract}

\section{Introduction}

Constantly increasing needs and expectations of man cause the improvement of existing and development of new products and technologies. However, the civilizational development has been accompanied by environmental transformations, posing new threats related to production, transport, exploitation, warehousing products and storage of hazardous waste. Despite the existence of safety measures, hazardous substances can be released to the environment as a result of occurrence, accidents, machinery breakdowns, extreme weather events or terroristic acts. Such occurrences may pose hazards to health and life of humans, cause material losses and environmental degradation [1-4]. Furthermore, such accidents cause huge economic losses and disrupt sustainable growth $[5,6]$.

Products as firefighting foams and extinguishing powders developed to the security or protect health, life and property, which are used by fire service units during rescue actions,

\footnotetext{
* Corresponding author: jrakowska@sgsp.edu.pl
} 
can be used only after satisfying technical and functioning requirements and when they have obtained permit to use. Both during firefighting actions and in chemical and ecological rescue, extinguishing and neutralizing agents are used, which can cause secondary environmental pollution [7,8]. Chemical substances used during rescue- and firefighting actions, i.e. extinguishing and neutralising agents ${ }^{1}$, must meet the requirements set out by norm and laws concerning their quality parameters, including the operation safety. For firefighting purposes, water, water solutions of extinguishing agents, extinguishing powders and gases are used. The suitable extinguishing agents: foam, powder or gas are selected depending on the type of the burning material, fire location, access to the substance applied and the price $[9,10]$.

Firefighting foams are dispersion of gas bubbles in a solutions containing surfactants, organic solvents, foam stabilizers and corrosion inhibitors. Firefighting foams are used to control and extinguish fires of flammable liquids $[10,11]$. They can also be used to prevent ignition of flammable liquids and for inhibiting reignition, in certain conditions, extinguish fires of solid combustibles. Firefighting foam is produced by mixing foam concentrate with water to prepare foam solution and foam is making through means of a discharge device. Generally, all types of foams will generate a foam blanket which forms an insulating barrier to heat, separates the flames from the fuel surface and suppresses the release of flammable vapors or large foam volumes can be used to flood room and fill cavities within a hazard. During the firefighting process, the foam is destroyed due a heat and fuel. Degradation reducing the foam's capacity to block fuel vapors.

Several properties important to the characterization of firefighting foam are expansion ratio (foamability), foam stability, fire performance class and burn-back resistance level. Foam expansion ratio is the coefficient of the volume of foam to the volume of the foam solution from which it was made. Foam stability can be defined as time needed for drain out the solution from the foam. The mostly assessed for firefighting foams stability are $25 \%$ or $50 \%$ drainage of the liquid from the foam. Foam effectiveness to extinguish the fire and burn-back resistance level are specifies in fire performance test conducted according standard procedures describing kind of fuel, size of the fire test, concentration of firefighting agent, method and equipment used to foam generate. The time needed to extinguish the fire from the start of foam application and until the time when all flames are extinguished is called as fire extinguishment time. The duration from the ignition of fuel in the burn-back pot to permanent full reinvolvement of the fire tray surface in flames.

Due to their chemical composition, foaming agents are classified as synthetic and protein-based agents. The group of synthetic agents includes concentrates based on hydrocarbon surfactants (together with A class agents, wetting agents ${ }^{2}$ ) or aqueous film forming agents (Aqueous Film Forming Foam - AFFF) containing both synthetic surfactants and fluorosurfactants. Protein-based agents are compositions containing hydrolysed proteins: protein agents (P), fluoroprotein agents (FP), and aqueous film forming fluoroprotein agents (FFFP) [4], [10]. Foams intended for extinguishing watermiscible liquids (AR) contain polymers that allow the formation of a layer separating fuel from oxygen.

To act effectively, suitable firefighting foam must be selected, which due their properties are dedicated to extinguish the specific kind of a flammable material, and these must be used in the right concentration. Using an inappropriate extinguishing agent can

\footnotetext{
1 The term "neutralising agents" refers to both acidic and alkaline chemical neutralizing substances as well as removal by absorption of the harmful medium, with no further hazardous effect.

${ }^{2}$ Wetting agent is a kind of chemical substance that increases the spreading and moistening properties of a water by lowering its surface tension in order to improve the penetration of solution into burning materials. Some manufacturers classify wetting agents as Class A foams that differ in the type of surfactants used in formulations.
} 
lead to e.g. lower capacity to generate foam (low expansion ratio) and reduced foam stability in contact with the substance extinguished. As a result, losses occur, both related to the hazardous event and those resulting from the introduction of an ineffective extinguishing substance to the environment. Taking a firefighting action and stopping the fire, reduces material and environmental losses resulting from the course of the event as well as threats to health and life of humans.

\section{Materials and methods}

For testing firefighting foam the standards methods $[12,13]$ as small-scale test was used. The methods of testing low expansion concentrates using the small-scale fire-test procedure $[12,13]$ are equivalent to the methods described in EN 1568, which provide the same fire parameters as those required by ISO $7203[12,13]$. Large-scale fire tests in accordance with the ISO 7203 or EN 1568 standards involve high costs and environmental pollution, therefore it is not recommended to perform it when the concentrate is tested in a quality control procedure. In my studies tests focused on foam making parameters; expansion ratio, drainage velocity, and extinguishing effectiveness; time to extinction and burn-back time. According to the requirements of the method [12] aliphatic hydrocarbon mixture (commercial heptane) as a fuel was used. In fire tests carried out in accordance with [13] acetone was used as the fuel. Each test requires filling into the tray with 9 litres of an appropriate fuel and into the burn-back pot 0.3 litres of the same fuel. All tests were conducted indoor with no wind and air temperature $20 \pm 0,5{ }^{\circ} \mathrm{C}$. Temperature of foam solutions and fuel was $18 \pm 1{ }^{\circ} \mathrm{C}$. The test results concern the quality of foam for synthetic foaming agents ( $\mathrm{S} 1$ for use in 3\% dilution, S2 and S3 for use in 6\% dilution), fluorine foam concentrate (FP1 - FP4 for $6 \%$ dilution and FP5-AR for use in 3\% dilution), aqueous filmforming agent in 3\% solution (AFFF-AR), fluoroprotein film-forming agent for use in concentration $6 \%$ (FFFP-AR) and protein foam concentrate in $6 \%$ solution (P). Fluoroprotein foaming agents (FP) were mixed with fresh and sea water. The parameters of the studied firefighting agents manufactured in 2014-2016 are listed in Table 1. Each experiment was repeated at least three times with a deviation less than $5 \%$ of the mean value.

Table 1. Firefighting foam parameters (producer information).

\begin{tabular}{|l|l|l|l|l|l|}
\hline $\begin{array}{l}\text { Firefighting } \\
\text { agent }\end{array}$ & $\begin{array}{l}\text { Viscosity at } \\
\mathbf{2 0} \mathbf{C}, \mathbf{m P a} \cdot \mathbf{s}\end{array}$ & $\begin{array}{l}\text { Biodegradation, } \\
\mathbf{\%} / \mathbf{2 8} \text { days }\end{array}$ & $\begin{array}{l}\text { Compatibility } \\
\text { with sea water }\end{array}$ & $\begin{array}{l}\text { Expansion } \\
\text { ratio }\end{array}$ & $\begin{array}{l}\mathbf{5 0 \%} \text { Drain } \\
\text { time, min }\end{array}$ \\
\hline S1 3\% & $16 \pm 2$ & $>90$ & - & $>8$ & $>15$ \\
\hline S2 6\% & $4 \pm 1$ & 88 & - & $>8$ & $>15$ \\
\hline S3 6\% & $10 \pm 2$ & NA $^{\dagger}$ & - & $>8$ & $>15$ \\
\hline AFFF AR 3\% & NA & NA & + & $>7$ & $10 \div 20$ \\
\hline FP1 6\% & $6 \pm 1$ & NA & - & $>7$ & $>15$ \\
\hline FP2 6\% & $4 \pm 1$ & NA & - & $>7$ & $>10$ \\
\hline FP3 6\% & $20 \pm 2$ & NA & + & $>7$ & $>9$ \\
\hline FP4 6\% & $6 \pm 2$ & NA & + & $>7$ & $>9$ \\
\hline FP5 AR 3\% & $>200$ & NA & - & $>7$ & $>12$ \\
\hline FFFP AR 6\% & $>850$ & $>92$ & - & $>6$ & $>9$ \\
\hline P 6\% & $<25$ & NA & + & $>7$ & $>9$ \\
\hline
\end{tabular}

${ }^{\dagger} \mathrm{NA}-$ not data available 


\section{Results and discussion}

Aqueous foams are concentrated dispersions of gas bubbles in water containing stabilizing agents such as surfactants, proteins or small particles. The foam structure is organized by the surfactant molecules adsorbed on liquid-gas interfaces. Foams are metastable systems and their stability depends primarily on the bubble size distribution related to physicochemical surfactant properties and dynamic processes running at the liquid-gas interface. The destabilization process occurs through: coalescence (rupture of liquid films between bubbles), gravity drainage and coarsening (gas diffusion between bubbles due to pressure differences) [14]. With the time elapsed since foam production end i.e. when the foam is aging, small bubbles shrink and the average bubble size increases.

Results obtained for firefighting foaming agent dedicated to preparing 3\% solution confirmed, that higher concentration does not improve foam quality (Fig. 1 and Fig. 2): foam blanket thickness (foam expansion ratio) and foam stability. The expansion ratio of studied foam was close to 8 for foam S1 and AFFF formed from solution from 3\% to $6 \%$. For solutions prepared from S2, P and FP1 higher expansion ratio versus concentration was proved. When foam is generated with method described in $[12,13]$ typical value of expansion ratio for synthetic foam is no less than 8 and for FP foam -6 . In experiment foam expansion ratio achieved adequate value for all types of concentrates only in $6 \%$ solution, but similar parameters for S1 and AFFF were observed. Slightly better foam stability for synthetic agent S1 was observed when concentration was higher than producer recommended, but for film forming agent AFFF there were no differences in the received values of the $50 \%$ drainage time of foam obtained from solutions 3-6\%. Stability of other foams increased with increase of concentration with the proviso that time to $50 \%$ drainage from AFFF foam was 12-18 minutes and for synthetic foam S2 about 15-23,5 minutes. As expected, after microscopic observation, greater stability of $\mathrm{S} 1$ foam than AFFF was confirmed.

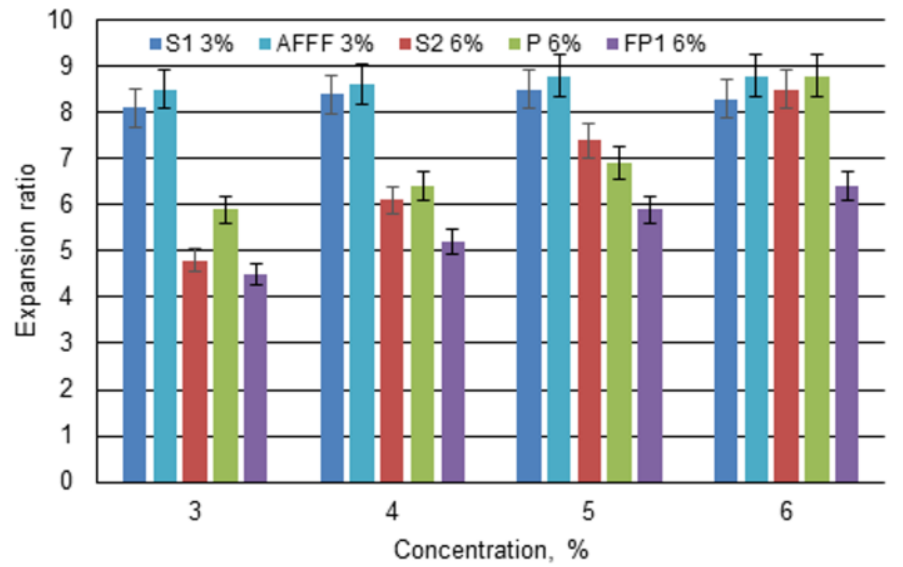

Fig. 1. Comparison of foam expansion ratio of the solution firefighting agents with different concentration. 


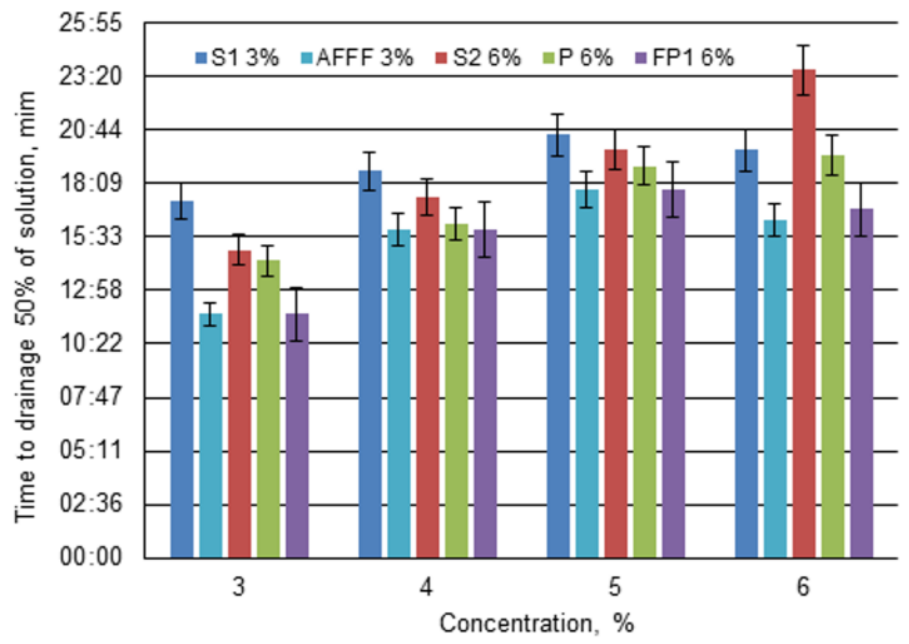

Fig. 2. Comparison of foam drainage time of the solution firefighting agents with different concentration.

Table 1. Comparison of foam parameters and extinguishing efficiencies of 3\% and $6 \%$ solution of film forming fluoroprotein foam concentrate FFFP AR tested according to ISO 7203-3: 2011 [13].

\begin{tabular}{|c|c|c|}
\hline \multirow{2}{*}{ Studied properties } & \multicolumn{2}{|c|}{ Results } \\
\hline & 3\% solution & 6\% solution \\
\hline Expansion ratio $^{3}$ & $4,5 \pm 0,2$ & $7,3 \pm 0,3$ \\
\hline Drainage time of $50 \%$ foam [min] & $11^{\prime} 07^{\prime \prime} \pm 33^{\prime \prime}$ & $14 ’ 22^{\prime \prime} \pm 42^{\prime \prime}$ \\
\hline Extinction time $[\mathrm{s}]$ & No extinction & $113 " \pm 5 "$ \\
\hline Burnback time [min] & - & $7 ’ 28 ” \pm 22 ”$ \\
\hline
\end{tabular}

Table 2. Comparison of foam parameters and extinguishing efficiencies of $3 \%$ and $6 \%$ solution of synthetic firefighting foam concentrate S3 tested according to ISO 7203-1: 2011 [12].

\begin{tabular}{|c|c|c|}
\hline \multirow{2}{*}{ Studied properties } & \multicolumn{2}{|c|}{ Results } \\
\hline & $3 \%$ solution & 6\% solution \\
\hline Expansion ratio $^{4}$ & $6,4 \pm 0,3$ & $8,5 \pm 0,4$ \\
\hline Drainage time of $50 \%$ foam [min] & $9 ’ 27 ” \pm 28 ”$ & $15^{\prime} 04^{\prime \prime} \pm 45^{\prime \prime}$ \\
\hline Extinction time [s] & $94 " \pm 5 "$ & $44 ” \pm 2 ”$ \\
\hline Burnback time [min] & 4’06” $\pm 12 ”$ & $14 ' 28^{\prime \prime} \pm 43^{\prime \prime}$ \\
\hline
\end{tabular}

- Compared to municipal water, lower foamability and worse the foam's stability was observed when preparing sea water solutions with foam concentrates containing surfactants not suitable for water with electrolytes. In the Figure 3 - 4 and Table 3, it was shown that, in the case of extinguishing agents designed to be used with seawater, these differences are significant. The fluoroprotein foam FP2 produced

${ }^{3}$ Water flow $1,625 \mathrm{dm}^{3} / \mathrm{min}$

${ }^{4}$ Water flow $0,75 \mathrm{dm}^{3} / \mathrm{min}$ 
with fresh water (according to producer recommendation) has 2 times better expansion ratio and stability than foam produced with sea water. For foam concentrates FP3 and FP4 which were designed to dilution in sea and fresh water the quality of foam was satisfactory both when formed with municipal or salty water and amounted over 8 . However, if for foam concentrate which is designed to be used only with fresh water FP2, and a sea water is applied, the foam quality can be substantially worse and expansion ratio is equal $4,50 \%$ drainage time is only 7 minutes. In such a case the foam has no ability to firefighting at all, or extinguishing a fire efficiently requires up to 3 times greater amount of the foam [10]. For foam generated in this work when expansion ratio for low expansion foam is smaller than 6 and time to drainage $50 \%$ of solution is below 7 minutes poor quality of foam was observed and lack of ability to fire extinction.

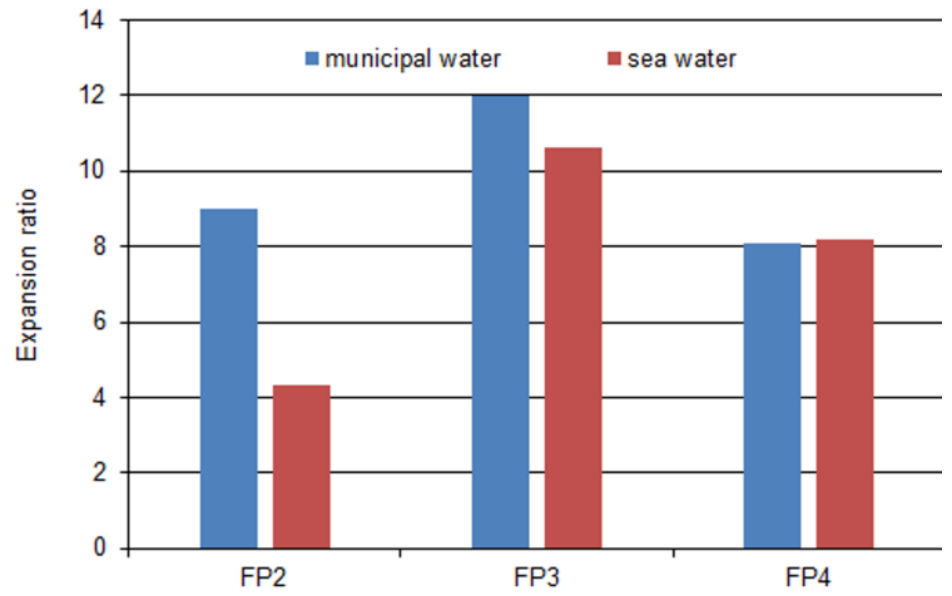

Fig. 3. Expansion ratio for fluoroprotein foams produced with fresh and sea water solutions in $6 \%$ concentration.

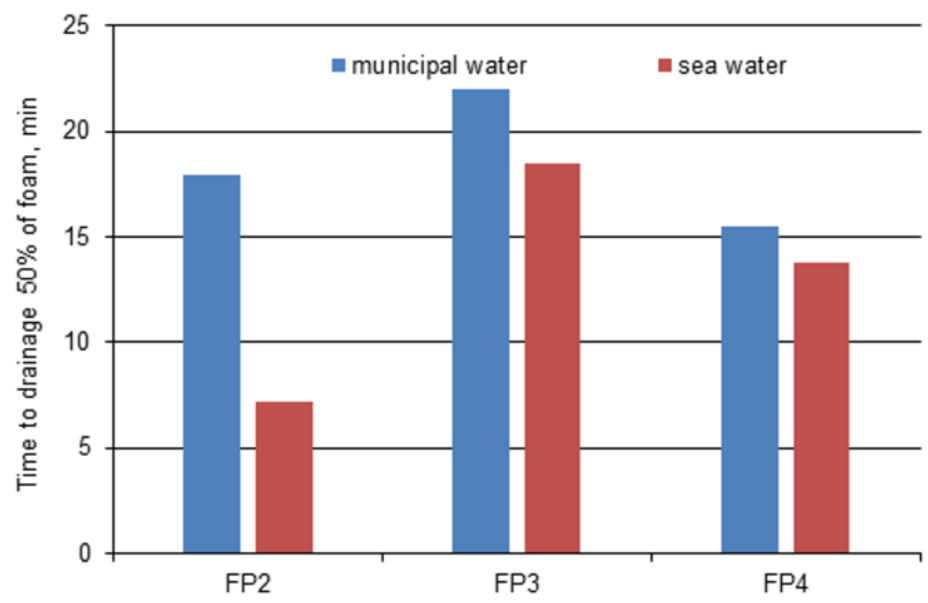

Fig. 4. Time to drainage $50 \%$ of fluoroprotein foams produced with fresh and sea water $6 \%$ solution.

For the fluoroprotein and synthetic foam, which are designed to use as $6 \%$ solutions (FP2 and S3) worse quality of foam were observed, when $3 \%$ concentration were applied. With regard to the concentration of $3 \%$ a considerably lower expansion ratio of the foam as 
well as a lower stability of the foam formed have been obtained than when using $6 \%$ solutions. Poor parameters of the foam quality reduces the firefighting effectiveness. This has been confirmed by results of firefighting effectiveness tests. The foam obtained from a fluoroprotein firefighting alcohol resistant agent (FFFP-AR) with a 3\% concentration failed to extinguish the test fire (Table1); the time needed to extinguish the fire with a foam obtained from a synthetic firefighting agent (S3) with a 3\% concentration was significantly longer (Table 2), which means a higher consumption of the extinguishing agent. On the other hand, quality parameter values obtained for solutions prepared according to producer instructions, meet the requirements, and the foam formed from $6 \%$ solutions was successful to extinguish the test fires. The extended time of fire reoccurrence demonstrates good insulating and cooling qualities of the foam which prevents from re-ignition of the fuel.

Table 3. Comparison of foam parameters and extinguishing efficiencies of 3\% solution of fluoroprotein firefighting foam concentrate FP5 AR tested according to ISO 7203-1: 2011 [13].

\begin{tabular}{|c|c|c|}
\hline \multirow{2}{*}{ Studied properties } & \multicolumn{2}{|c|}{ Results } \\
\hline & fresh water & Sea water \\
\hline Expansion ratio $^{4}$ & $9,0 \pm 0,4$ & $4,3 \pm 0,2$ \\
\hline Drainage time of $50 \%$ foam [min] & $17^{\prime} 58^{\prime \prime} \pm 53^{\prime \prime}$ & 7'10” $\pm 21 ”$ \\
\hline Extinction time [s] & $54 ” \pm 2 ”$ & no extinction \\
\hline Burnback time [min] & $21^{\prime} 06 " \pm 63 ”$ & - \\
\hline
\end{tabular}

Just like salinity, water pollution can affect the capacity of foam forming from a solution and the foam's stability. As demonstrated by studies carried out using heavily polluted surface waters [15], the foam forming capacity from a solution of foam forming agents and the stability of the foam change according to the type and level of contamination. The presence of salts and metal ions causes the worsening of the foam forming capacity and the foam's stability. As a result, also the time needed to fight the fire is longer (Tabele 3) and the foam formed is characterized by lower insulation and lower capacity to protect from re-ignition (shorter or no burn-back resistance).

Using an inappropriate extinguishing agent or an appropriate one in the wrong way causes an unjustified release into the environment of substances which are not indispensable components of extinguishing agents designed for specific material groups. When performing a firefighting action, it is therefore important to apply effective extinguishing agents with the lowest required concentration and the smaller amount needed to suppress the fire, which reduces possible environmental impact of firefighting foam.

\section{Conclusions}

The extinguishing efficiency of foam results from a combination of many characteristics that raise the effectiveness of firefighting: foam properties, used equipment, fuel and fire type as well ambient conditions. The tests methods were standardized procedures to be highly reproducible. All of the tests were conducted indoor to eliminate impact of ambient conditions: air temperature and humidity and wind speed. The proved relationship of extinguishing media type and its concentration with ability to fire suppression is reproducible.

During all tests, it was shown that to extinguish fires faster and safer the foam should be made from solution in concentration recommended by the manufacturer, so as to generate

\footnotetext{
${ }^{4}$ Water flow $0,75 \mathrm{dm}^{3} / \mathrm{min}$
} 
the right amount of foam and its stability. If the expansion ratio is very low (below 6) and the foam is not stable, it does not provide separation of fuel from the air until the combustible material cools and reduces the evaporation of flammable vapors. As a result, the fire lasted longer even until the fuel burned out. The longer time to extinction the fire observed during tests means higher consumption of firefighting foam and water while using too low agent's concentration or to in unsuitable scope of use.

\section{References}

1. H. Holemann, Fire Safety Sci. 4, 61 (1994)

2. Stockholm Convention, Regulation (EC) No 850/2 (2009)

3. W. Ruppert, D. Verdonik, C. Hanauska, Hughes Associates Inc., Baltimore (2005)

4. B. Król, K. Prochaska, Ł. Chrzanowski, Fire Techn. 48, 173 (2012)

5. 2015 Annual Global Climate and Catastrophe Report, AON Benfield, (2016)

6. C. Afonso, J. Crespo, Green Separation Processes: Fundamentals and Applications (Wiley 2006)

7. Hazard Assessment of Perfluorooctane Sulfonate (PFOS) and its Salt, OECD (2002)

8. J. Seow, Fire Fighting Foams with Perfluorochemicals - Environmental Review, Pollution Response Unit (Australia 2013)

9. A. Mizerski, M. Sobolewski, Zeszyty Naukowe SGSP 35, 33, (2007)

10. J. Rakowska, K. Radwan, B. Porycka, Fire Safety Techn. 39, 67 (2015)

11. S.A. Magrabi, B.Z. Dlugogorski, G.J. Jameson, Chem. Eng. Sc. 54, 4007 (1999)

12. ISO 7203-1:2011

13. ISO 7203-3:2011

14. I. Cantat, Foams - Structure and Dynamics (Oxford University Press 2013)

15. J. Rakowska, B. Porycka, Evaluation of the effectiveness of using contaminated surface water in firefighting operations, Józefow: CNBOP-PIB (2012) 